\title{
Diurnal variation of precipitation over the Carolina Sandhills region
}

\author{
A Wootten ${ }^{1, *}$, S RAman ${ }^{1}$ and A Sims 2 \\ ${ }^{1}$ Department of Marine, Earth and Atmospheric Sciences, North Carolina State University, \\ Raleigh, NC 27695-8208, USA. \\ ${ }^{2}$ State Climate Office of North Carolina, Raleigh, NC 27695-8208, USA. \\ *e-mail: amwootte@ncsu.edu
}

\begin{abstract}
The Carolina Sandhills are known to have an area of maximum precipitation on its western boundary during the summer mainly due to differences in soil types. Statistical analysis was performed on summer precipitation data from automated weather stations in the Carolinas, along the Sandhills for the years 2001 to 2006. Statistically significant difference was observed between the day and night precipitation amounts. A case study also revealed the diurnal pattern of convective precipitation.

North American Mesoscale (NAM) model forecasts for the summers of 2004 to 2006 were evaluated using observations. The model underpredicted precipitation significantly during nights. A numerical simulation using Weather Research and Forecast (WRF) model was performed for August 9-11, 2001 and the forecasts were compared with observed precipitation data. The model precipitation forecasts were better for daytime as compared to the night. This feature is attributed to model physics not capturing cloud-radiation interaction processes dominant during nights. Although this study is for a specific region in the US, results are applicable for other regions for similar conditions.
\end{abstract}

\section{Introduction}

Forecasting convection in the summer is a challenge for meteorologists due to the mesoscale and local scale effects. These local effects are enhanced and many times are caused by horizontal gradients in surface heat fluxes induced by the presence of different soils with different heat capacities or by variations in land use. Parameterizations in most of the weather forecast models experience problems in accounting for the variations of such heat flux gradients that cause low level convergence and convection initiation (Marshall et al 2003). Another problem the models face is in the simulation of the convection caused by cloud-radiation interaction (Bony and Emanuel 2005; Arakawa 2004), a process that is more dominant during the night hours.
In the Sandhills region of North Carolina, a strong gradient in soil type is present with soil changing from clay to sand. The influence of soil type and vegetation on convection has been well documented. Segal et al (1988) found that the effect of vegetation and soil contrasts on thermally induced flow is similar to the sea breeze circulation. Their study suggested that flows with the intensity of a sea breeze can develop when vegetation is dense over an extended area given favourable environmental conditions. Ookouchi et al (1985) also studied these thermally induced flows and found similar results. Their results indicated that on flat terrain a large contrast in soil moisture availability results in thermal circulations that approach the intensity of sea breeze circulations. Hong et al (1995) showed similar results with differences in vegetation over an area. These

Keywords. Sandhills; diurnal convection; heat flux gradients; cloud-radiation interaction. 


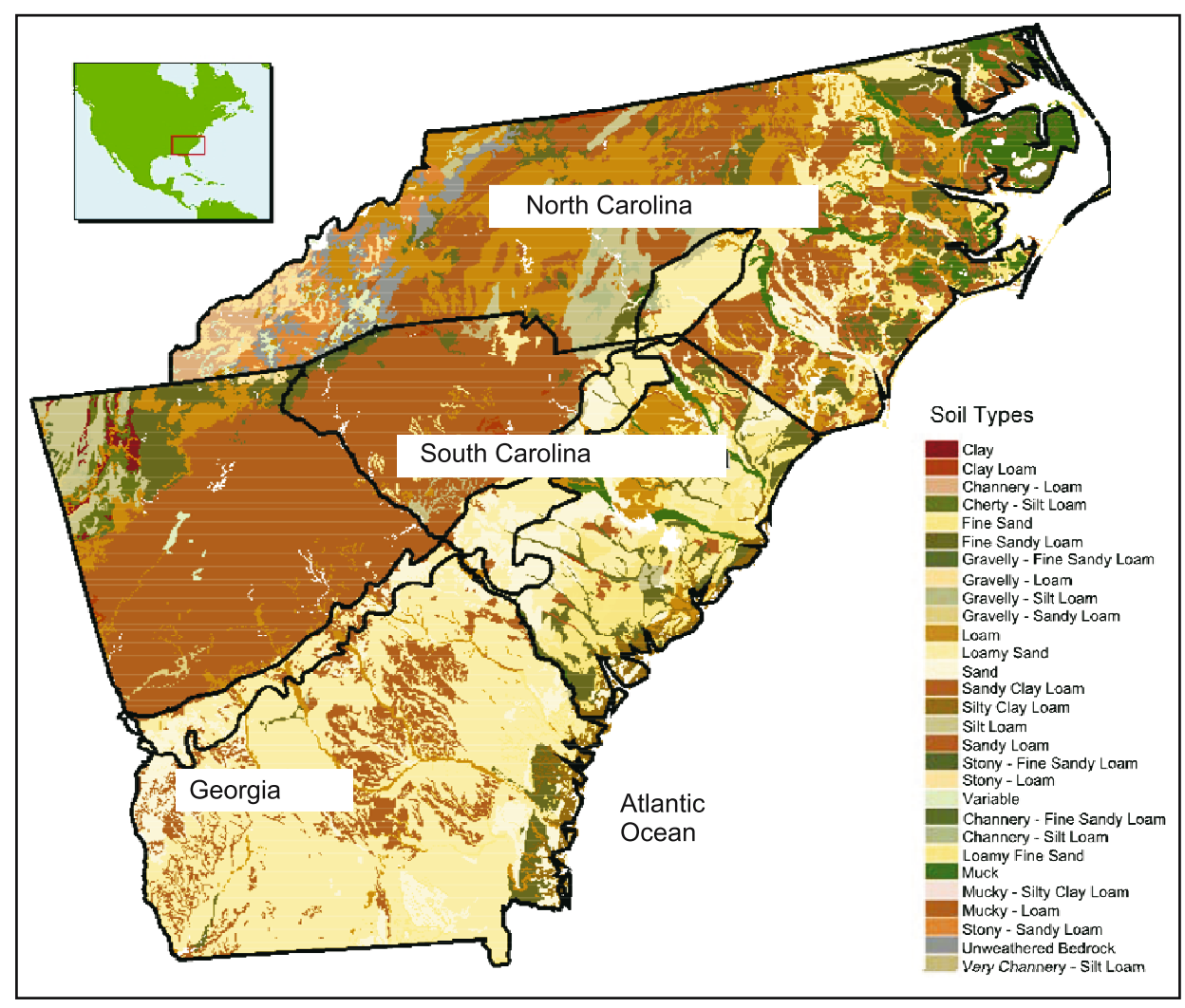

Figure 1. Soil type distribution for North Carolina, South Carolina and Georgia.

investigators showed that the thermal circulations that form between vegetated areas and dry steppes form convective clouds. These convective clouds can either persist or dissipate depending on the existence of low level moisture and instability in the area.

Several investigators have studied soil and vegetation influence on convection. Mahfouf et al (1987) used a two-dimensional mesoscale model with a detailed representation of the soil and vegetation to study convection over contrasting land use regions. They analyzed a sea breeze over land with no synoptic flow over flat terrain and observed the response. Their results suggested that the transition zone between bare soil and vegetation is the preferred location for the initiation of moist convection. While Mahfouf et al (1987) demonstrated such transition zone convergence in model runs, Koch and Ray (1997) used the combined capabilities of the WSR-88D Doppler radar, Geostationary Operational Environmental Satellite (GOES) imagery and surface observations to demonstrate this transition zone convergence between the Piedmont and the Coastal Plains of North Carolina. The existence of this circulation in the Sandhills caused by differential heating of contrasting soil types between the Sandhills and Coastal Plain has also been shown by numerical simulations in recent years (Raman et al 2005). These simulations reveal that the coastal sea breeze circulation often interacts with the Sandhills circulation to initiate deep convection in this region. Most recently, numerical modeling experiments using four different soil and vegetation patterns suggested that the presence of the clay-sand transition zone produces a surface heat flux gradient and enhanced convergence and the soil contrasts appeared to dominate over the vegetation contrasts (Boyles et al 2007).

The Sandhills convection has been partly to blame for many intense convection events in the Carolinas. It is of interest to study the convection caused by local influence such as the Sandhills. Hence only summer convection in the Sandhills region is selected in the research reported in this paper with little or negligible interaction with large scale weather.

To best evaluate the diurnal variation of convection over the Sandhills region, we perform a statistical analysis using observations over a period of six years to determine if there is a strong difference between diurnal and nocturnal precipitation. We also evaluate the forecast precipitation using the North American Mesoscale (NAM) model in predicting diurnal variation of convection for three summers. A case study using the Weather Research 


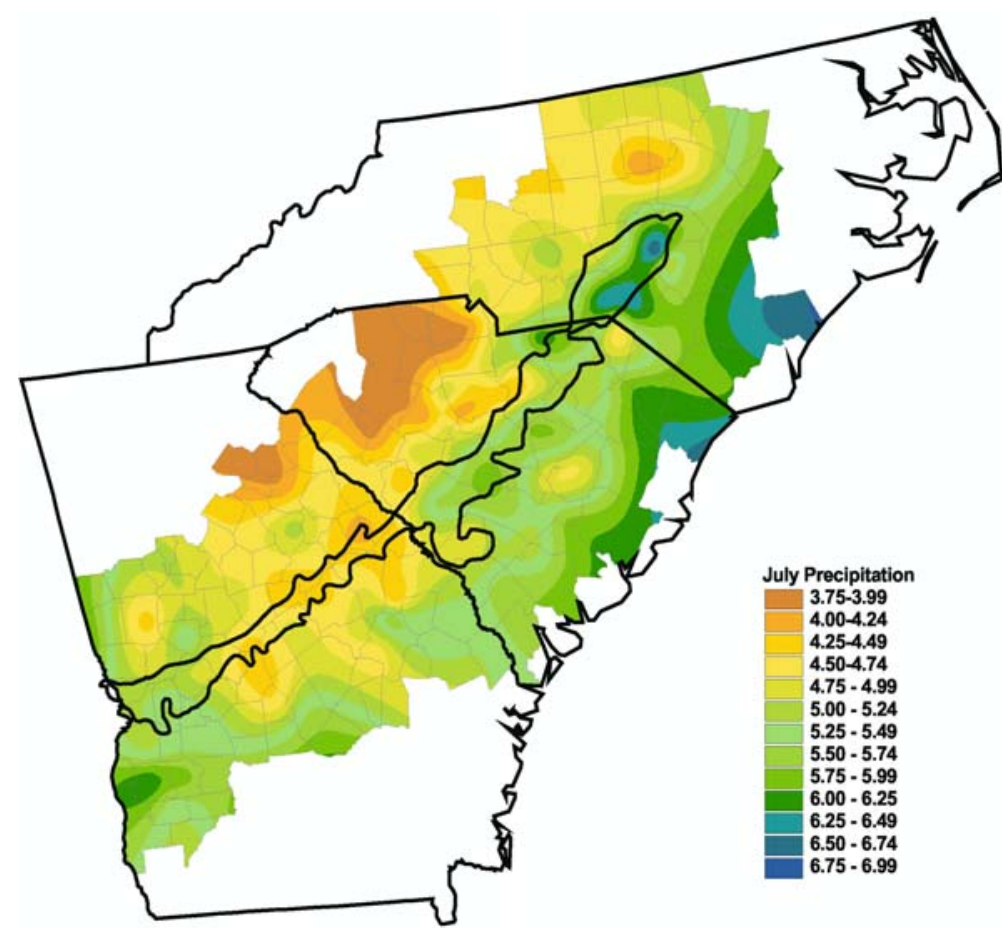

Figure 2. Thirty-year normal precipitation for the month of July, 1960-1999.

and Forecasting (WRF) model is also presented to illustrate the diurnal variation of convection and precipitation as well as the ability of these models to capture these processes. Additionally, we discuss how cloud-radiation interaction may play a role in the formation of nocturnal convection enhancement.

\section{Mesoscale processes in the Sandhills - contrasting soil types}

The Sandhills is an area of sandy soil that runs from the northeast to the southwest from central North Carolina through western Georgia (figure 1). Along the west side of this region there is clay, while along the east side there is a mix of soils with clay predominant in the north. The sharpest transition between soil types is on the western boundary of the Sandhills, where strong convection tends to develop. This transition is especially evident in the Carolinas where higher precipitation occurs during the summer over the Sandhills compared to regions to the east and west. Thirty-year normal precipitation (Raman et al 2005) for the month of July over this region indicates a transition from a drier region in the west to wetter areas to the east along the Sandhills (figure 2). Locations of all the stations used in this study, which included stations from the NC ECONet (North Carolina Environmental and Climate Observing Network) and the National Weather Service ASOS Network
(Automated Surface Observing Stations) are shown in figure 3 . These stations are located in different soil types as shown in figure 1. In this study we consider stations along the coast of the Carolinas and further inland in order to be able to differentiate precipitation in the Sandhills resulting from surface heat flux contrasts from more organized sea breeze convection that can move into the Sandhills area. The precipitation difference between Sandhills and non-Sandhills regions suggests the possibility that the mesoscale processes involved at the soil boundary are impacted by the heat capacities of the two dominant types of soil. Each soil type has a distinct specific heat capacity $\left(c_{p}\right)$, which in turn causes the sensible heat flux and the ground heat flux from each type of soil to differ. Sandy soil has a heat capacity of roughly $830 \mathrm{~J} \mathrm{~kg}^{-1} \mathrm{~K}^{-1}$, while clay has a heat capacity of about $1380 \mathrm{~J} \mathrm{~kg}^{-1} \mathrm{~K}^{-1}$. This results in larger sensible heat flux over the Sandhills region during day time when there is a maximum in incoming solar radiation with the heat flux gradients from sand to clay. This gradient in sensible heat flux is the trigger which can result in convective precipitation in this region. Figure 4 shows a line diagram of the convection processes that can occur in the presence of a heat flux gradient. In some instances, the low level convergence on the warm side of the soil boundary can result in deep clouds and convective precipitation during the daylight hours. However, if atmospheric stability inhibits the formation of deep clouds, the process can form shallow clouds which linger into the night. 


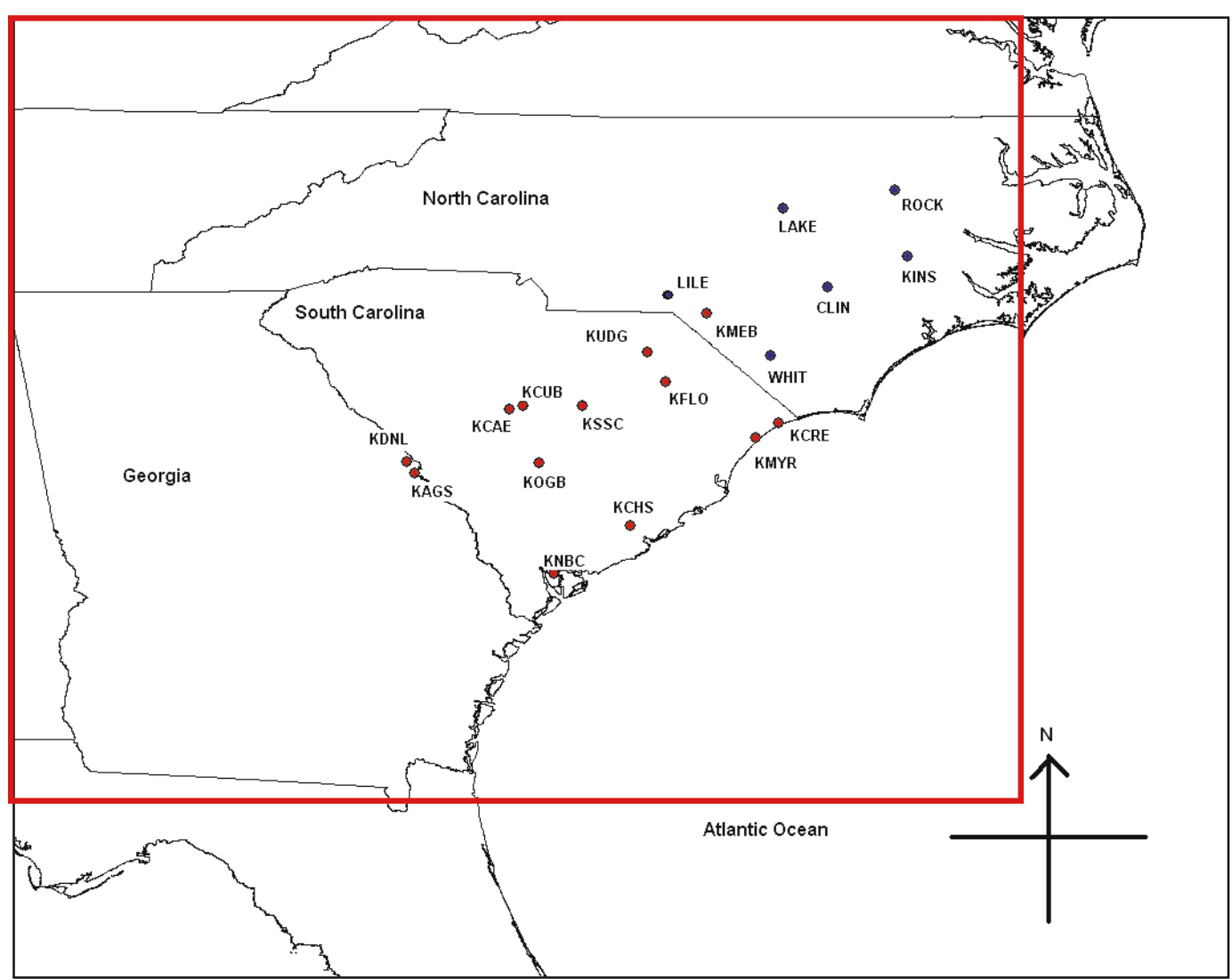

Figure 3. Map of stations used, ECONET in blue and ASOS in red. The red box indicates the domain of the inner nest for the WRF 3.0 simulation.

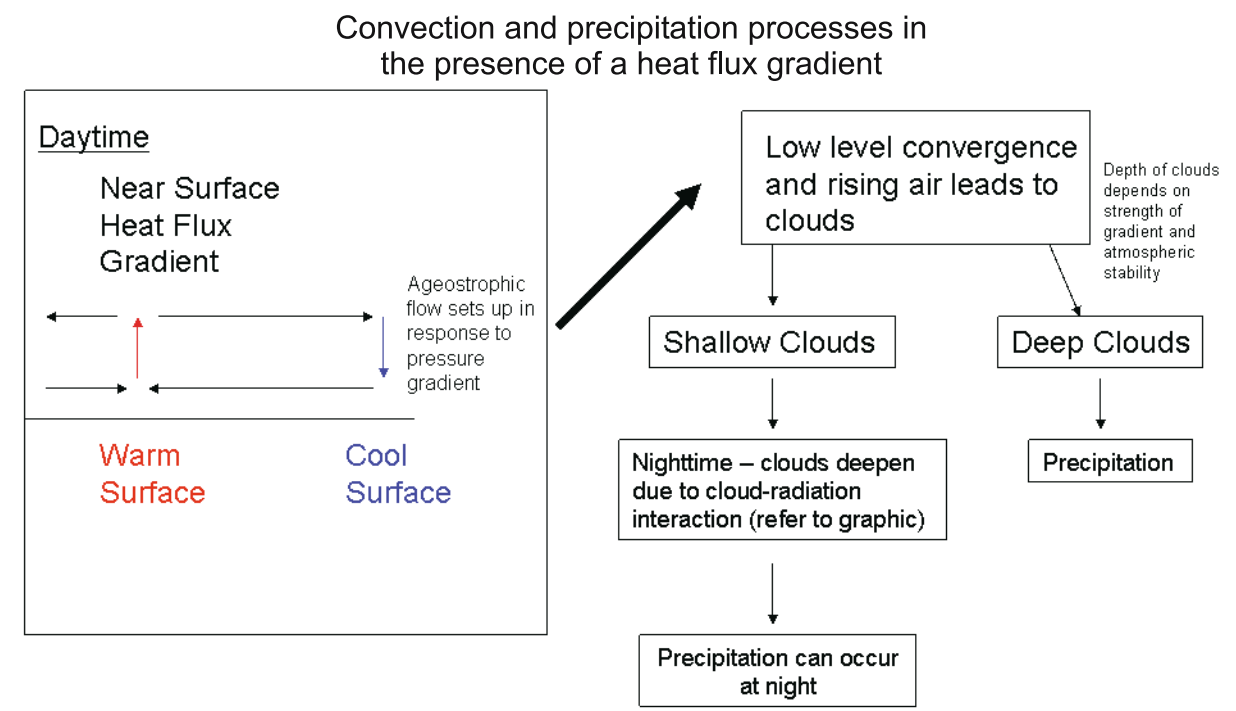

Figure 4. Initiation of convection and precipitation due to surface heat flux gradients during day time.

These shallow clouds can be deepened as a result of cloud-radiation interaction (figure 5). This interaction process warms the base of the cloud with the heat released from the soil beneath the cloud, causing the cloud to deepen as the warm air at the surface rises. As the cloud deepens, the top cools, and entrainment in the cloud begins, causing the cloud to deepen further. Therefore, the shallow clouds that result from daytime convergence can grow at night through this interaction process. However, the horizontal surface heat flux gradient resulting in circulations that caused these clouds to 

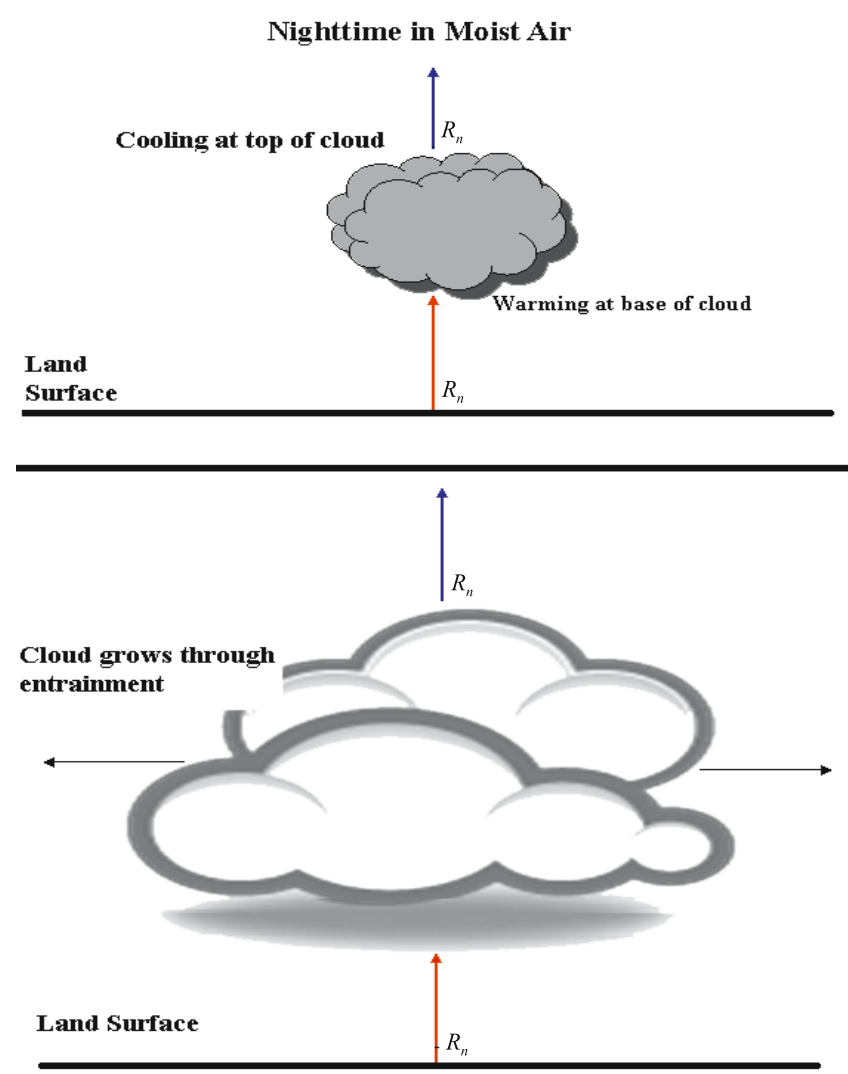

Figure 5. Night time process related to cloud growth. $R_{n}$ is net radiation. Shallow cloud tends to grow through entrainment by warming at the base of the cloud and cooling at the top. Horizontal differential heating between the clouds and the environment and moisture availability are also important factors.

form does not completely stop at night. During the night, the gradient reverses because of larger storage in the clay region as compared to sand. This is evident from the surface energy budget:

$$
R_{N}=H+H_{L}+H_{G}+\text { Storage }
$$

where $R_{N}$ is the net radiation flux, $H$ is the sensible heat flux, $H_{L}$ is the latent heat flux and $H_{G}$ is the ground heat flux. Depending on the mixture of minerals in the two soils, the heat capacity of clay can be higher by a factor of two thus resulting in a larger sensible heat flux over sand.

To verify this hypothesis, station data from a pair of stations were analyzed to show the differences in heat flux between clay and sandy soil over time. Observations from Lilesville (LILE) and Clinton (CLIN) were considered (figure 3). CLIN is a representative station for areas with clay soil, while LILE is representative of the Sandhills region. Information such as location and metadata for each station used in this paper is provided in table 1. Both the stations are equipped with two levels of instruments measuring wind speed, wind direction, air temperature, and humidity at $2 \mathrm{~m}$ and $10 \mathrm{~m}$ in addition to other parameters such as solar radiation, soil temperature, and soil moisture. From the observations at both levels, turbulent sensible heat flux could be estimated using vertical temperature gradients, and wind shear in line with the Monin Obukov similarity theory (Arya 2001). Variation of the sensible heat flux at the two stations for June 1, 2007 is shown in figure 6. Heat flux at LILE located in the Sandhills is consistently larger than the values at CLIN. Maximum observed heat flux at LILE (from the Sandhills region) is $400 \mathrm{~W} \mathrm{~m}^{-2}$ and the maximum at CLIN is $250 \mathrm{~W} \mathrm{~m}^{-2}$. The two stations are only about $50 \mathrm{~km}$ apart. This creates a significant horizontal heat flux gradient possibly triggering convection and low level clouds during day time. Soil temperatures at a depth of $10 \mathrm{~cm}$, shown in figure 7 , also indicate a horizontal gradient. Lilesville reaches a maximum near-surface temperature of about $34.5^{\circ} \mathrm{C}$ earlier than Clinton where maximum soil temperature was about $30.5^{\circ} \mathrm{C}$. Similar results were found for other days with the difference in heat fluxes significantly increasing if there was precipitation previous day. Clay retains moisture longer than sand thus experiencing smaller heat flux as compared to sand. The resulting difference in temperature and in sensible heat flux shows that there is a gradient present between sand and clay soils. This gradient lingers into the night hours and could mean a significant difference between day and night precipitation in the Sandhills.

\section{Climatological analysis of diurnal precipitation variation}

In this study, observations from stations in the NC ECONet and the National Weather Service ASOS distributed between the Sandhills region and the coastal region of North Carolina and South Carolina were used. Rainfall data recorded during the passage of tropical cyclones were removed as it is not considered mesoscale convection of interest. The data was checked for quality, and observations that were flagged by the State Climate Office of North Carolina as poor quality were not used in this study. Also any of the hourly observations not recording rainfall were discarded, since we focused on deep convection. The rainfall data was then separated into day and night, assuming day to be $11 \mathrm{Z}$ to $23 \mathrm{Z}$ and night to be $23 \mathrm{Z}$ to $11 \mathrm{Z}$. 
Table 1. Automated weather stations used in the paper.

\begin{tabular}{llcc}
\hline Station ID & \multicolumn{1}{c}{ Station name } & Latitude & Longitude \\
\hline KUDG & Darlington County Airport, SC & 34.44 & -79.89 \\
KFLO & Florence Airport, SC & 34.18 & -79.72 \\
KCRE & Grand Strand Airport, SC & 33.81 & -78.72 \\
KMYR & Myrtle Beach AFB, SC & 33.67 & -78.92 \\
KCHS & Charleston Airport, SC & 32.89 & -80.04 \\
KNBC & Beaufort MCAS, SC & 32.47 & -80.72 \\
KAGS & Bush Field, GA & 33.36 & -81.96 \\
KDNL & Daniel Field, GA & 33.46 & -82.03 \\
KOGB & Orangeburg Municipal Airport, SC & 33.45 & -80.85 \\
KCAE & Columbia Metropolitan Airport, SC & 33.93 & -81.11 \\
KCUB & Owens Downtown Airport, SC & 33.97 & -80.99 \\
KSSC & Shaw AFB, SC & 33.97 & -80.47 \\
ROCK & Upper Coastal Plain Res. Stn., NC & 35.89 & -77.68 \\
LAKE & Lake Wheeler Rd. Field Lab., NC & 35.72 & -78.67 \\
WHIT & Border Belt Tobacco Res. Stn., NC & 34.41 & -78.79 \\
KMEB & Laurinburg-Maxton Airport, NC & 34.79 & -79.36 \\
KINS & Cunningham Res. Stn., NC & 35.30 & -77.57 \\
CLIN & Horticultural Crops Res. Stn., NC & 35.02 & -78.28 \\
LILE & NC Electric Cooperative Anson Peaking Plant, NC & 34.97 & -79.92 \\
\hline
\end{tabular}

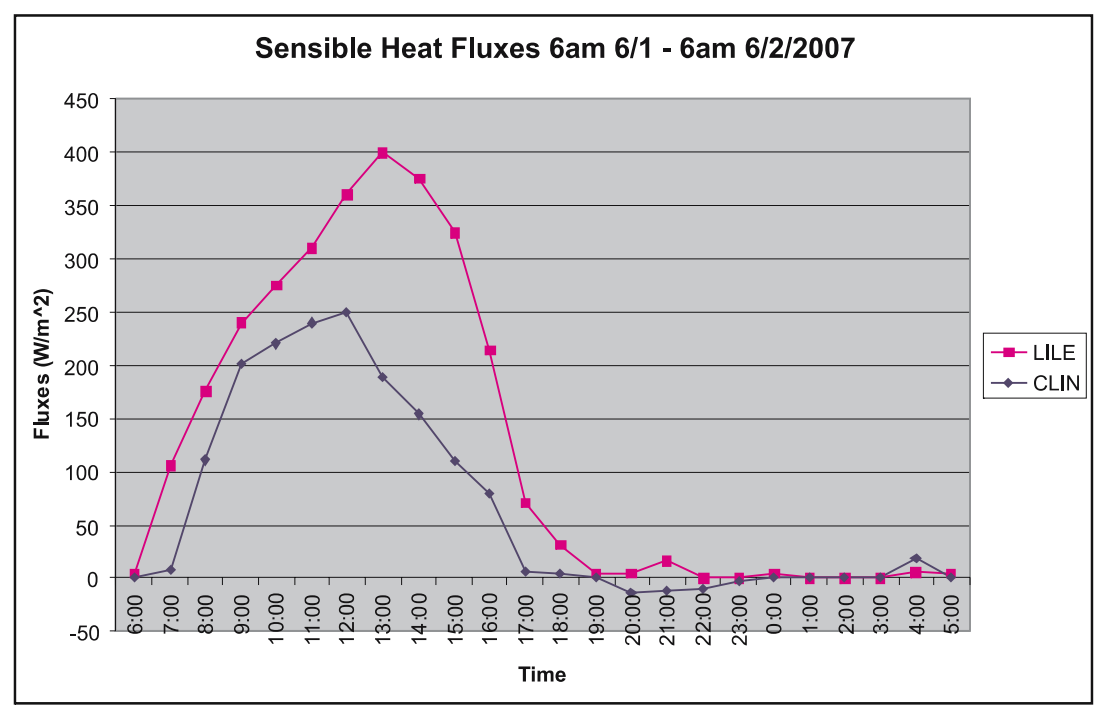

Figure 6. Soil temperature $\left({ }^{\circ} \mathrm{C}\right)$ for CLIN and LILE for June 1-2, 2007.

\subsection{Statistical analysis of the climatological observations}

In order to determine if there is truly a difference between day and night precipitation amounts during the months of May through September, specific statistical tests were performed on precipitation data from stations in the Sandhills region, for May through September for the years 2001 to 2006. Fourteen stations were used for this analysis with their data separated into day and night amounts for each month. A two-sample $T$-test was performed on the data to determine a significant difference between day and night precipitation amounts (Moore and McCabe 2006).

As expected from the initial analysis there is a significant difference between day and night precipitation in the Sandhills region. However, the diurnal variation in this precipitation also seems to change with each month as shown in figure 8 for the Sandhills region. There is a difference between the total precipitation occurring during the day and the total precipitation occurring during the night for each month. There is also a difference between the total precipitation occurring during the day and the total precipitation occurring 


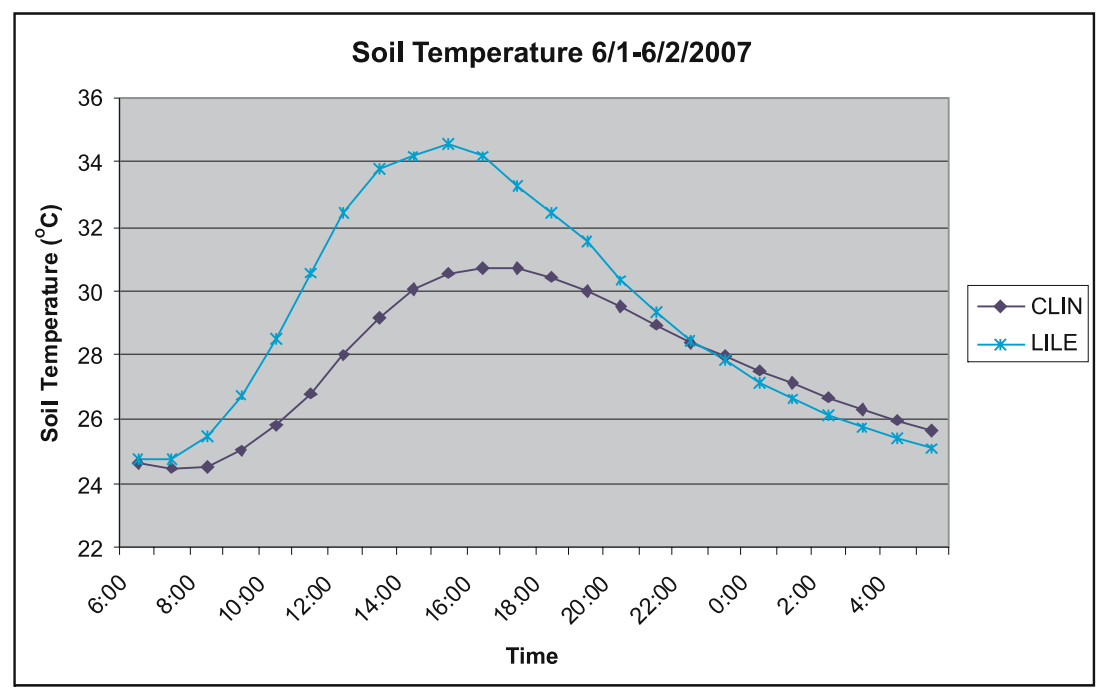

Figure 7. Sensible heat flux $(\mathrm{H})$ in $\mathrm{W} \mathrm{m}^{-2}$ for CLIN and LILE for June 1-2, 2007.

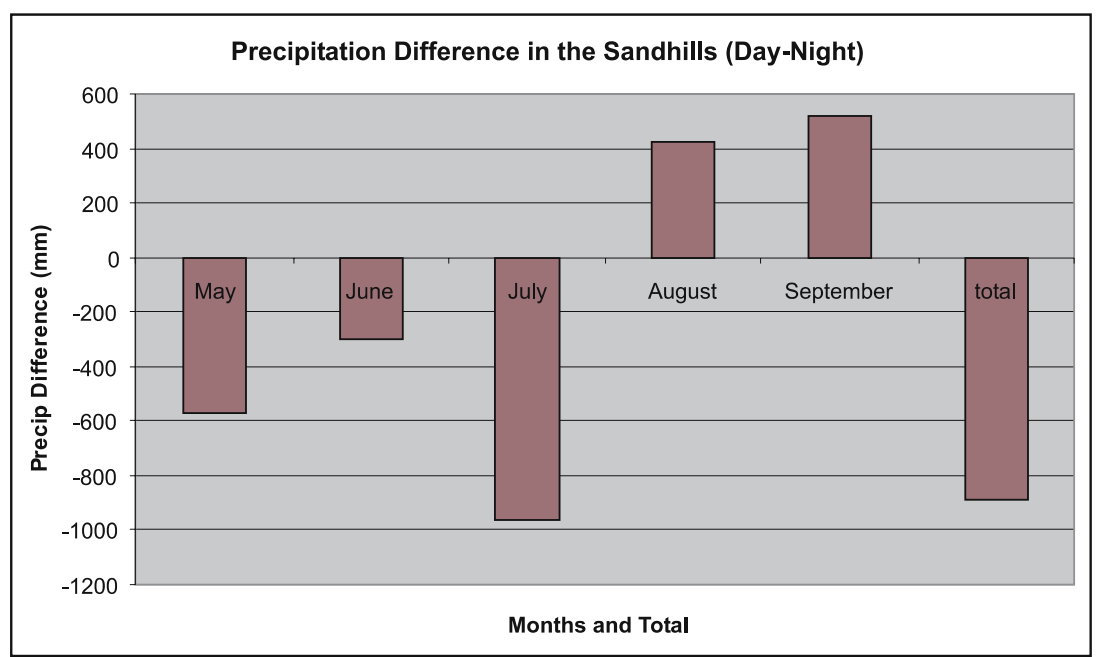

Figure 8. Precipitation differences - total night minus total day precipitation for each month (in $\mathrm{mm}$ ).

during the night over the whole time period; i.e., from May through September from 2001-2006. While each month shows a difference between day and night precipitation, May and July show the greatest difference between day and night precipitation $(-577.85 \mathrm{~mm}$ in May, $-973.33 \mathrm{~mm}$ in July). The months of June, July and August contributed the greatest amount of night precipitation to the total precipitation difference in the Sandhills (3416.3 mm in June, $3665.2 \mathrm{~mm}$ in July, $3601.7 \mathrm{~mm}$ in August, overall night precipitation $14996 \mathrm{~mm}$ ). It is apparent from figure 8 that more precipitation occurred during the day times in August and September in the Sandhills (4033.52 mm during the day in August, $2156.46 \mathrm{~mm}$ during the day times in September). The greatest apparent difference in precipitation appears to be in July (figure 8), while the next greatest differences appear to be in May and September. The difference between the summed day precipitation and summed night precipitation for each month for all the sites in the Sandhills is shown in figure 9. Observations plotted in figure 9 indicate that almost all the stations recorded more precipitation at night in July leading to the largest difference for the whole region. Similarly in September, most of the Sandhills stations recorded more precipitation during the day time than at night. However, greatest difference does not always translate to a statistically significant difference. Therefore, it becomes necessary to check the apparent precipitation difference against the results of the $T$-test, specifically using $p$-values. The $p$-values for the $T$-test performed for the Sandhills for each month is given in table 2. In this $T$-test, the level of significance is 0.05 . The greatest apparent difference is in July 


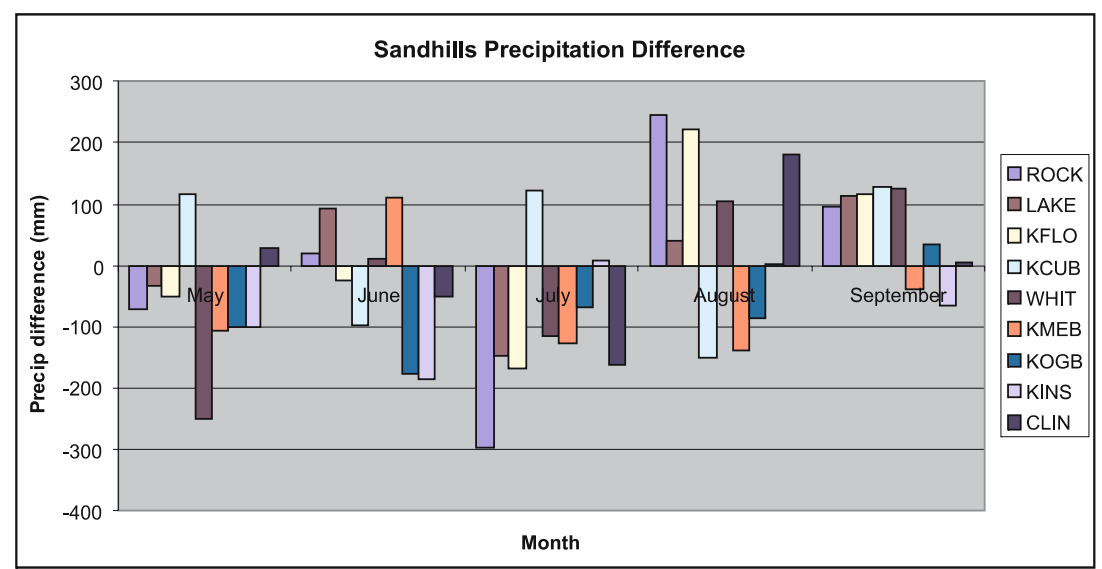

Figure 9. Comparison of precipitation difference for Sandhills stations: Night precipitation total for each month subtracted from day precipitation total for each month $(\mathrm{mm})$.

and September. However, in terms of the $T$-test only July shows a statistically significant difference between average day and night precipitation in the Sandhills. For this case, we are defining a marginally significant difference when the $p$-value is between $\alpha$ and $\alpha+0.05$. In this case, that means the $T$-test will show a marginally significant difference between day and night precipitation when the $p$-value is between 0.05 and 0.1 . Therefore, September and May show a marginally significant difference between day and night precipitation. The pattern evident in the data suggests that there is a strong diurnal pattern in precipitation in the Sandhills, with this pattern being most evident in July, with most of the precipitation for that month occurring at night. While not statistically significant June also showed more precipitation occurring at night in the Sandhills region. From the previous discussion on the heating difference between soils, it is possible that the difference in soil temperature and sensible heat flux between sand and clay has caused more night time convective precipitation to occur during the peak of summer.

\section{Evaluation of mesoscale forecasts}

\subsection{Comparison of model forecasts with observations}

In this section, the capability of an operational weather forecasting model to predict diurnal variation of precipitation is discussed. The $6 \mathrm{~h}$ archived precipitation data from the North American Mesoscale (NAM) model was retrieved. Analysis was performed for the summers of 2006, 2005 and 2004, with the four $0-6 \mathrm{~h}$ total precipitation for each day at $12 \mathrm{~km}$ resolution. This data was for the month of June, July and August. In order
Table 2. The p-values for day vs. night precipitation in the Sandhills region for each month for the period 2001-2006.

\begin{tabular}{lc}
\hline Month & $p$-value \\
\hline May & 0.0958 \\
June & 0.3767 \\
July & 0.0265 \\
August & 0.3778 \\
September & 0.0514 \\
\hline
\end{tabular}

to simplify the forecast validation, the observed precipitation data for each day for the same time period was separated into $6 \mathrm{~h}$ groups which matched the $0-6 \mathrm{~h}$ precipitation sums. For example, all the observations from $0600 \mathrm{Z}$ to $1200 \mathrm{Z}$ were grouped together to match the $1200 \mathrm{Z}$ $0-6 \mathrm{~h}$ total precipitation. Welch's $T$-test was then performed for the difference between observed and forecast precipitation, along with a calculation for sum difference and percent error, which are defined as:

$$
\begin{gathered}
\text { Sum difference }=\sum \text { Obs. }-\sum F X \\
\%_{\text {error }}=\left(\sum \text { Obs. }-\sum F X\right) / \sum \text { Obs. }
\end{gathered}
$$

where $\sum$ Obs. is the sum of the observed precipitation for a given 6-hour time period for the summer, and $\sum F X$ is sum of all the $0-6 \mathrm{~h}$ for the same time period for the summer. For example, the $\sum$ Obs. for $0600 \mathrm{Z}$ is the sum of all observed precipitation between $0600 \mathrm{Z}$ and $1200 \mathrm{Z}$, while the $\sum F X$ for $0600 \mathrm{Z}$ is the sum of all the $0600 \mathrm{Z}$ to 


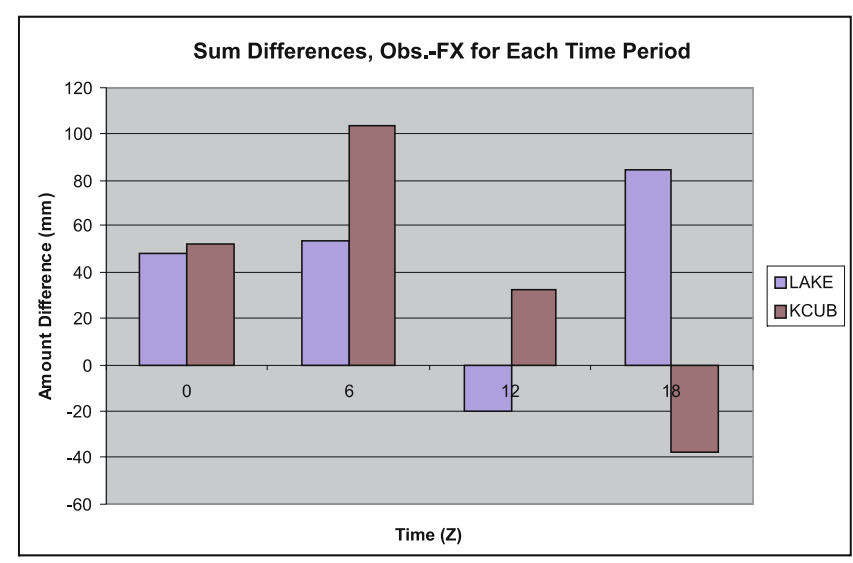

Figure 10. NAM precipitation difference between observed and forecasts for summer 2006. A negative bar represents the model overpredicting and a positive bar represents the model underpredicting.

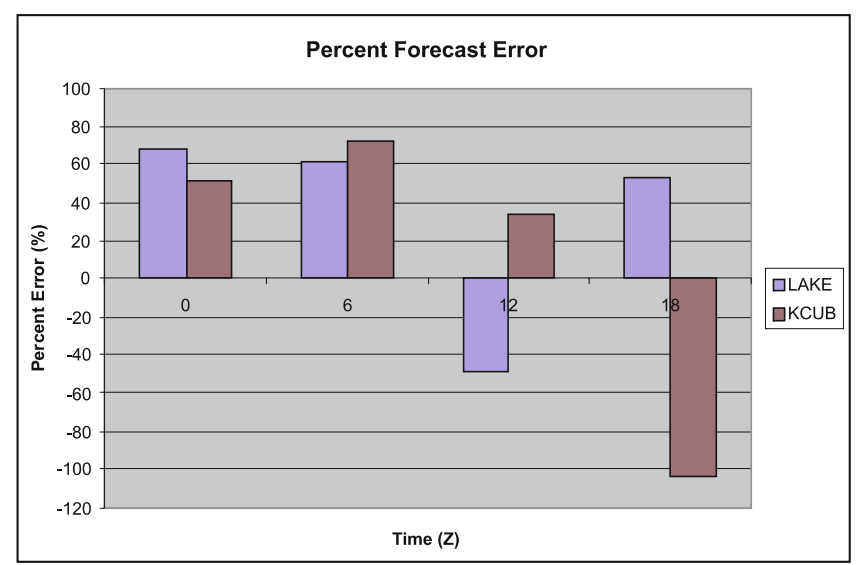

Figure 11. NAM percent error for each model run for the summer 2006: A negative bar represents the model overpredicting and a positive bar represents the model underpredicting.

$1200 \mathrm{Z}$ total precipitation data. The $0-6 \mathrm{~h}$ total precipitation data are for $0600 \mathrm{Z}, 1200 \mathrm{Z}, 1800 \mathrm{Z}$ and
$0000 \mathrm{Z}$. The statistical analysis described above was performed for all the model data involved along with the Welch's T-test on the average difference between observed and forecast precipitation. The results of these analyses showed many clear discrepancies between the NAM forecast precipitation and the observed precipitation.

\subsection{Diurnal precipitation forecast validation for the summers of 2004, 2005 and 2006}

The NAM (North American Mesoscale) model was compared to the observations in order to study how an operational weather model captures the observed diurnal variation in precipitation. This section focuses specifically on Columbia, SC (KCUB) which lies in the heart of Sandhills, and Lake Wheeler, NC (LAKE) which is to the north of the Sandhills. For the sake of brevity, these two stations are considered here. This analysis was performed for the summers of 2006, 2005, and 2004 , using a simple sum difference calculation and a percent error calculation along with the Welch's $T$-test on the average difference mentioned previously. Analysis for the summer 2006 is shown in figure 10. During the overnight hours (approximately from $0000 \mathrm{Z}$ to $1200 \mathrm{Z}$ ), the NAM appears to be underpredicting precipitation at KCUB. NAM underpredicts by $55.56 \mathrm{~mm}$ and $103.18 \mathrm{~mm}$ for $0000 \mathrm{Z}$ to $0600 \mathrm{Z}$ and $0600 \mathrm{Z}$ to $1200 \mathrm{Z}$, respectively. For the same time period at the LAKE, NAM is again underpredicting by $48.14 \mathrm{~mm}$ and $53.54 \mathrm{~mm}$, respectively. In contrast, during the daylight hours (approximately $1200 \mathrm{Z}$ to $0000 \mathrm{Z}$ ), NAM has a mixture of underprediction and overprediction at both stations. This is also apparent in the percent error shown in figure 11. However, the greatest percent error occurred for the $0000 \mathrm{Z}$ to $0600 \mathrm{Z}$ at LAKE and $1800 \mathrm{Z}$ to $0000 \mathrm{Z}$ at KCUB. The model overpredicted by $103 \%$ for KCUB and

Table 3. Percent error and p-values for the forecast validation for 2006.

\begin{tabular}{lccrrr}
\hline Time period & $\begin{array}{c}\text { Observed } \\
(\mathrm{mm})\end{array}$ & $\begin{array}{c}\mathrm{FX} \\
(\mathrm{mm})\end{array}$ & $\begin{array}{c}\text { Obs. }-\mathrm{FX} \\
(\mathrm{mm})\end{array}$ & $\begin{array}{c}\text { Percent } \\
\text { error }\end{array}$ & $p$-values \\
\hline LAKE & & & & & \\
0000-0600 Z & 70.358 & 22.214 & 48.144 & 68.427 & 0.014 \\
$0600-1200 \mathrm{Z}$ & 88.138 & 34.603 & 53.535 & 60.740 & 0.105 \\
$1200-1800 \mathrm{Z}$ & 41.656 & 61.864 & -20.208 & -48.511 & 0.211 \\
$1800-0000 \mathrm{Z}$ & 159.766 & 75.573 & 84.193 & 52.698 & 0.251 \\
KCUB & & & & & \\
$0000-0600 \mathrm{Z}$ & 101.425 & 48.864 & 52.560 & 51.822 & 0.066 \\
$0600-1200 \mathrm{Z}$ & 144.305 & 41.128 & 103.177 & 71.500 & 0.029 \\
$1200-1800 \mathrm{Z}$ & 95.524 & 63.188 & 32.336 & 33.851 & 0.321 \\
$1800-0000 \mathrm{Z}$ & 36.853 & 74.956 & -38.104 & -103.394 & 0.090 \\
\hline
\end{tabular}

Sum differences; Difference (Obs. - FX); FX - Forecast data; Significant difference when $p$-value $<0.05 ;$ Obs. - Observed data. 

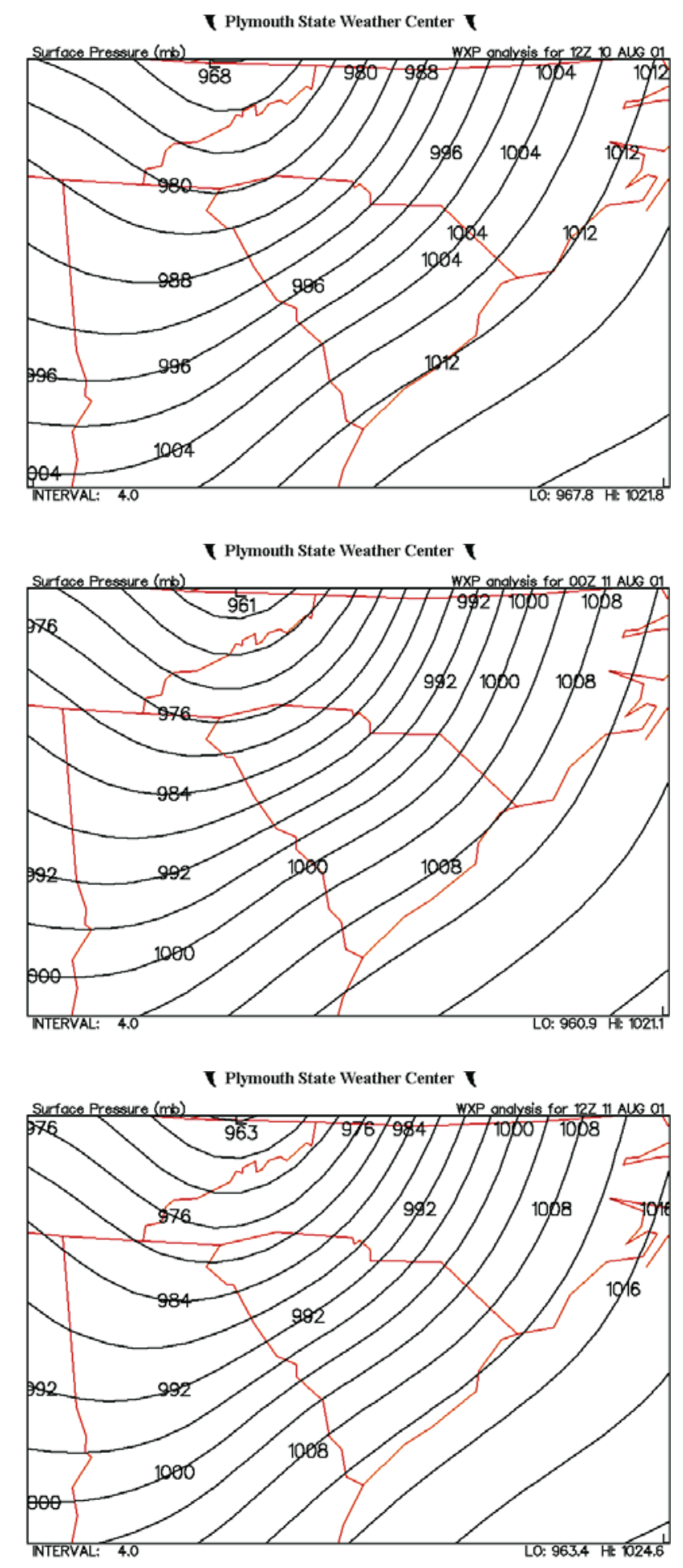

Figure 12. Station pressure map centered over Columbia, SC from $1200 \mathrm{Z}$ August 10, 2001 (top) to $1200 \mathrm{Z}$ August 11, 2001 (bottom).

underpredicted by $68.4 \%$ for LAKE. Therefore, at KCUB the largest sum difference is during the time period from $0600 \mathrm{Z}$ to $1200 \mathrm{Z}$ (at night) while the largest percent error is during the period from $1800 \mathrm{Z}$ to $0000 \mathrm{Z}$ (during the day). However, as previously mentioned, an apparently large difference between observed and forecast total precipitation or a large percent error does not indicate a statistically significant difference. So a Welch's $T$-test was performed to determine if there is significant difference between observed and NAM forecast precipitation. The $p$-values from the $T$-test, the percent error and the difference in millimeters are shown in table 3 . This $T$-test also had a level of significance equal to 0.05 . While the $0600-1200 \mathrm{Z}$ period had the largest sum difference, the $p$-value for this time period also indicated that the difference between observed and forecast precipitation at this time is significant at KCUB, but had a percent error of only $71.5 \%$. For LAKE, the $0000-0600 \mathrm{Z}$ period had the largest sum difference and the largest percent error, and the $p$-value from the $T$-test indicated a significant difference between observed and forecast precipitation. The $0000-0600 \mathrm{Z}$ period and 1800-0000 Z period showed a marginally significant difference at KCUB. For LAKE, no other time periods showed a marginally significant difference between observed and forecast precipitation.

The results of the analysis of summer 2005 and summer 2004 were very similar to summer 2006, with few exceptions. During the time period from 0000-0600 Z both stations in both summers showed that the observed precipitation was significantly larger than the forecast precipitation. In each summer, the difference at KCUB for this time period was more significant than the difference at LAKE. For example, the $p$-value for KCUB during this period in 2004 was $2.58 \times 10^{-10}$, but was only 0.0148 for LAKE. This was a similar pattern to summer 2006 with a more significant difference. However, in the time period from $0600 \mathrm{Z}$ to $1200 \mathrm{Z}$, both stations and both summers indicated that the NAM was overpredicting precipitation. This pattern was not consistently significant for both summers, however, the NAM underpredicted precipitation at both stations in summer 2006. Therefore, the results of the analysis for this time period are somewhat inconsistent. However, NAM consistently underpredicted precipitation during the late night hours from $0000 \mathrm{Z}$ to $0600 \mathrm{Z}$, which was a significant or marginally significant result for both stations in all three summers. For the summers 2004 and 2005, NAM was consistently underpredicting precipitation in the daylight hours $(1200 \mathrm{Z}$ to $0000 \mathrm{Z}$ ), but the difference between observed and forecast precipitation was not significant in only half the cases.

The statistical testing on the average difference in conjunction with the sum difference suggests that the NAM significantly underpredicts precipitation during the period from $0000 \mathrm{Z}$ to $0600 \mathrm{Z}$ at LAKE both stations. It is possible that this underprediction of convection is the result of the NAM cumulus scheme interacting poorly 


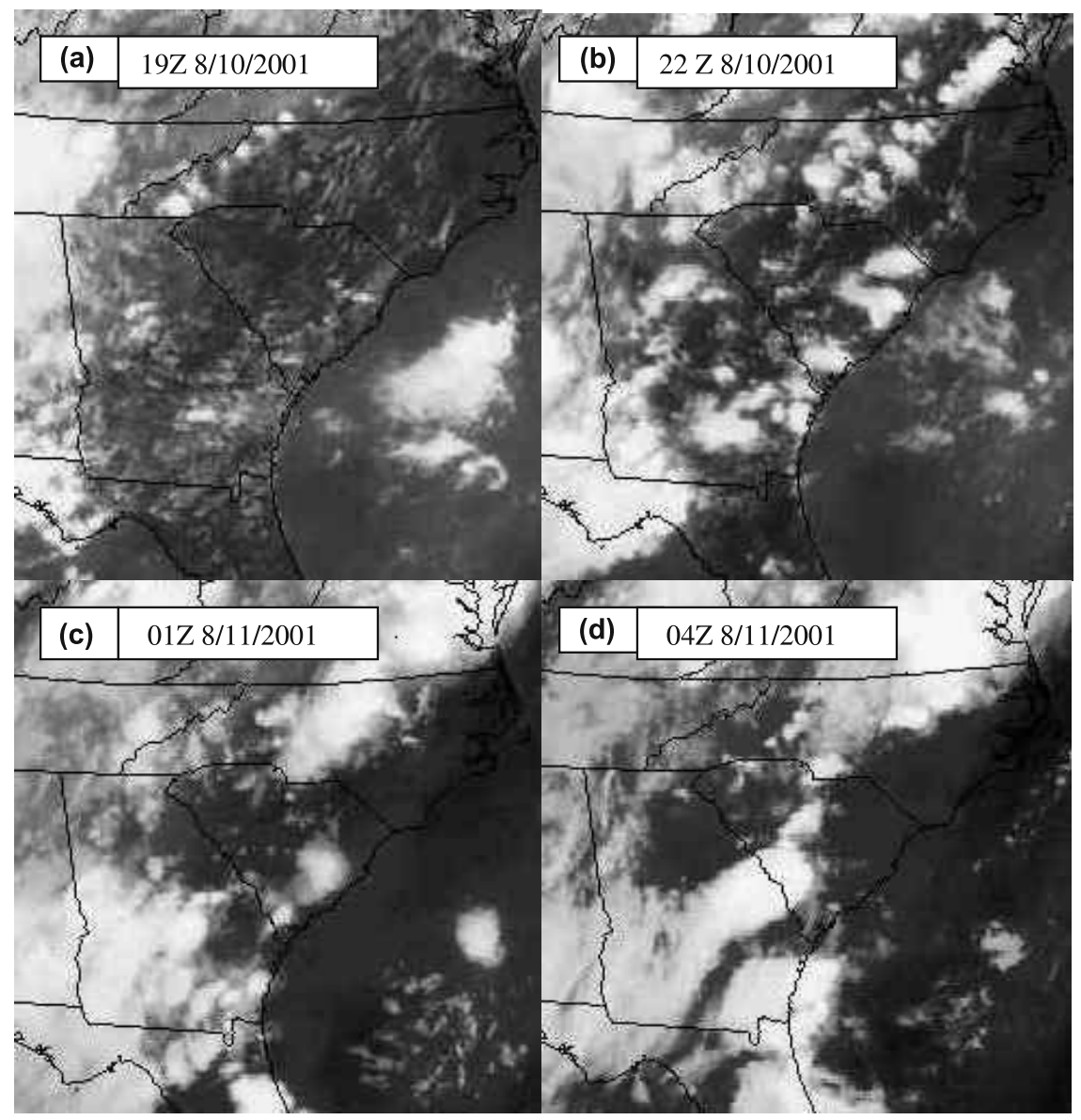

Figure 13. (a-d) GOES 8 IR satellite images from $1900 \mathrm{Z}$ August 10, 2001 to $0400 \mathrm{Z}$ August 11, 2001.

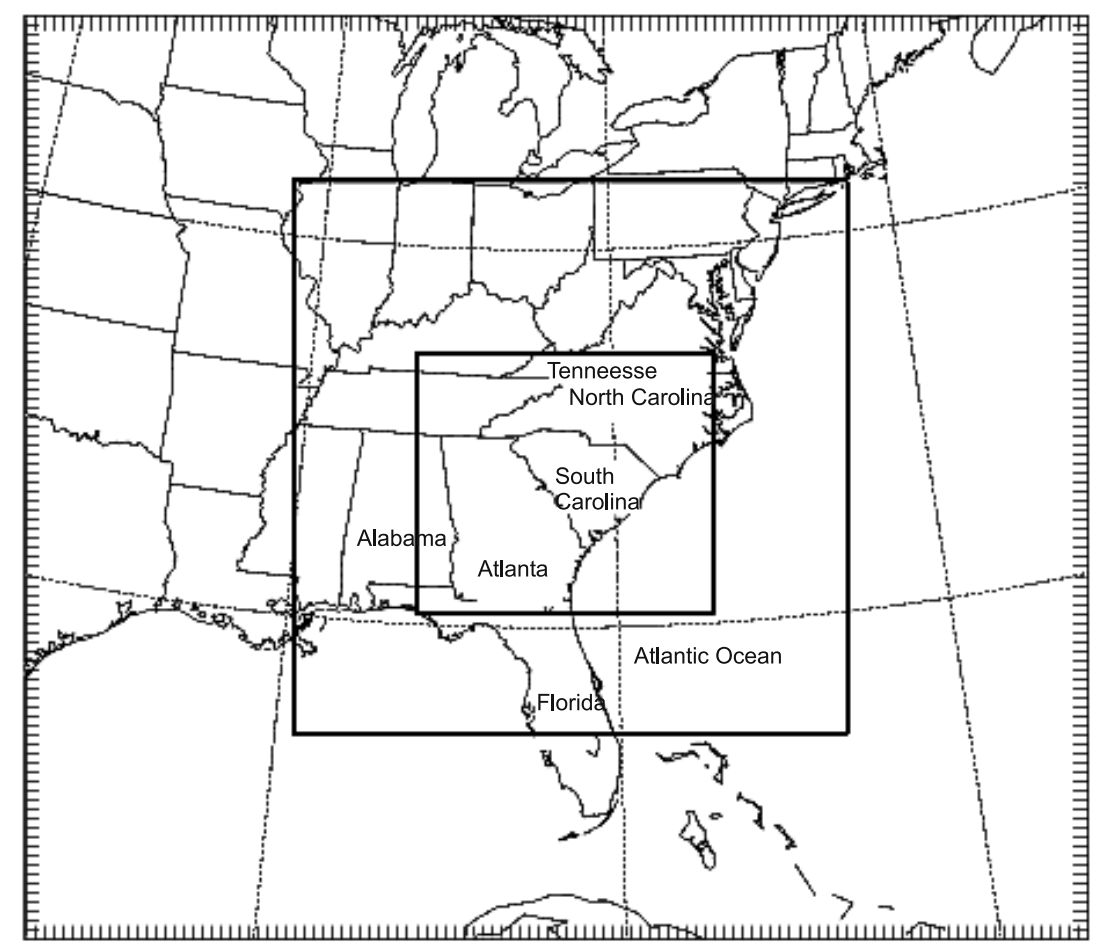

Figure 14. Triple nested WRF simulation domains used in this study. 

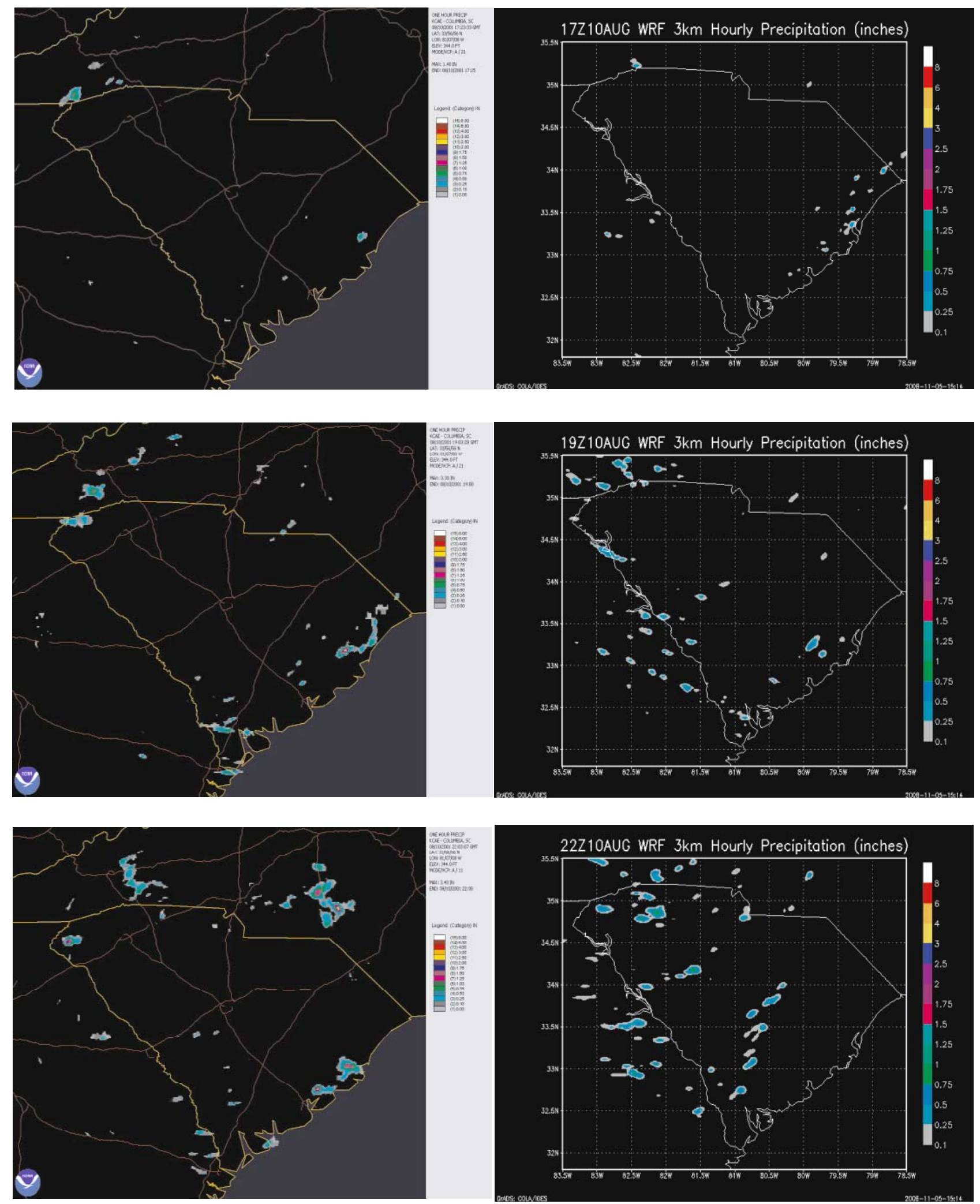

Figure 15. NEXRAD one hour precipitation (left) compared to WRF forecast hourly precipitation (right) from $1700 \mathrm{Z}$ to $2200 \mathrm{Z}$ on August 10, 2001 (1200 EST-1700 EST, August 10, 2001). Scale 0-8 inches (0 to $203.2 \mathrm{~mm}$ ).

with the radiation scheme in the model, which would result in little to no forecasted convection resulting from cloud-radiation interaction at night.
This is a possibility we will discuss further with a numerical simulation of a Sandhills deep convection event, but we also acknowledge that 


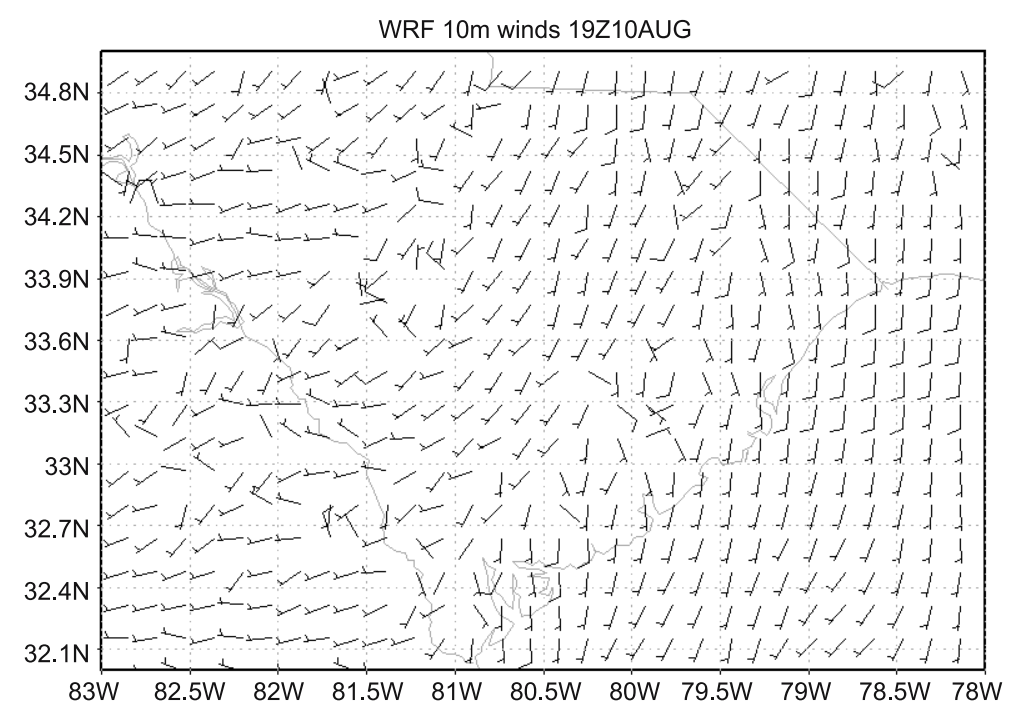

Figure 16. WRF forecast local $10 \mathrm{~m}$ winds for $1900 \mathrm{Z}$ on 10 August 2001.

the analysis should be done with more stations to draw a more robust conclusion on the success of the NAM model.

\section{Numerical simulation of convection, 9-11 August 2001}

An example of the delayed release of heat from clay soil is evident in the diurnal convection pattern over the Sandhills region during the period from August 9, 2001 to August 11, 2001. During this time period, high pressure dominated most of the southeast United States, with a weak low pressure system passing far to the north of the Sandhills. A trailing cold front from this low became wedged against the western slopes of the Appalachian mountains during the morning of August 10, resulting in precipitation over the far western portion of North Carolina and South Carolina during the day. However, this cold front did not move over the mountains during this time period; hence there was no significant synoptic forcing over the Sandhills. By the end of the period, $0000 \mathrm{Z}$ August 12, the low pressure center over the northeast United States moved over the northern Atlantic Ocean. A weak low formed in the lee of the Appalachians during the late afternoon of August 11, and persisted on August 12.

Considering the timing of this low, we consider the time period from $1200 \mathrm{Z}$ August 10 to $1200 \mathrm{Z}$ on August 11 for the mesoscale convection analysis, since this period exhibits only weak synoptic forcing in the Carolinas (figure 12).

Convection was evident on August 10 over the southeastern United States from the GOES 8 IR data (figure 13a-d). For comparison with observed precipitation, a WRF simulation was performed for $72 \mathrm{~h}$ from $0000 \mathrm{Z}$ August 9 to $0000 \mathrm{Z}$ August 12, 2001. A triple-nested domain was used with a 27-km resolution outer grid, 9-km resolution middle grid and $3-\mathrm{km}$ resolution inner grid with 41 vertical levels (figure 14). The simulation was initialized with North American Regional Reanalysis data and used the following parameterization schemes: WSM5 microphysics scheme, Noah Land Surface Model, MYJ PBL scheme, RRTM radiation scheme, and the Kain-Fristch convection scheme on the two outer grids, with explicit cloud physics only for the inner most domain. In order to focus more on the Sandhills region, three one hour precipitation measures from the period of 1700 $2200 \mathrm{Z}$ from the WSR-88D Doppler radar located at Columbia, SC shows the convection along side hourly precipitation at the same times in the same period from WRF version 3.0 (figure 15).

Convection occurring along the coast during the day is likely the result of the sea breeze circulation, while the convection along the mountains is likely associated with a weak surface low in east Tennessee, as evidenced by the GOES 8 IR imagery (figure 13a). WRF also captures the precipitation from this convection during the day time hours (figure 15). Around $2200 \mathrm{Z}$, convection is still noticeable along the coast from the sea breeze circulation, but convective initiation has begun at the edges of the Sandhills by this time (figure 13b). During the day the WRF forecasts are consistent with the sea breeze-induced convection along the coast which is evident in the modeled wind barb patterns along the coast (figure 16). The day time precipitation around the Sandhills is consistent with the observed precipitation with only a slightly different spatial pattern. However, during the night time hours this 

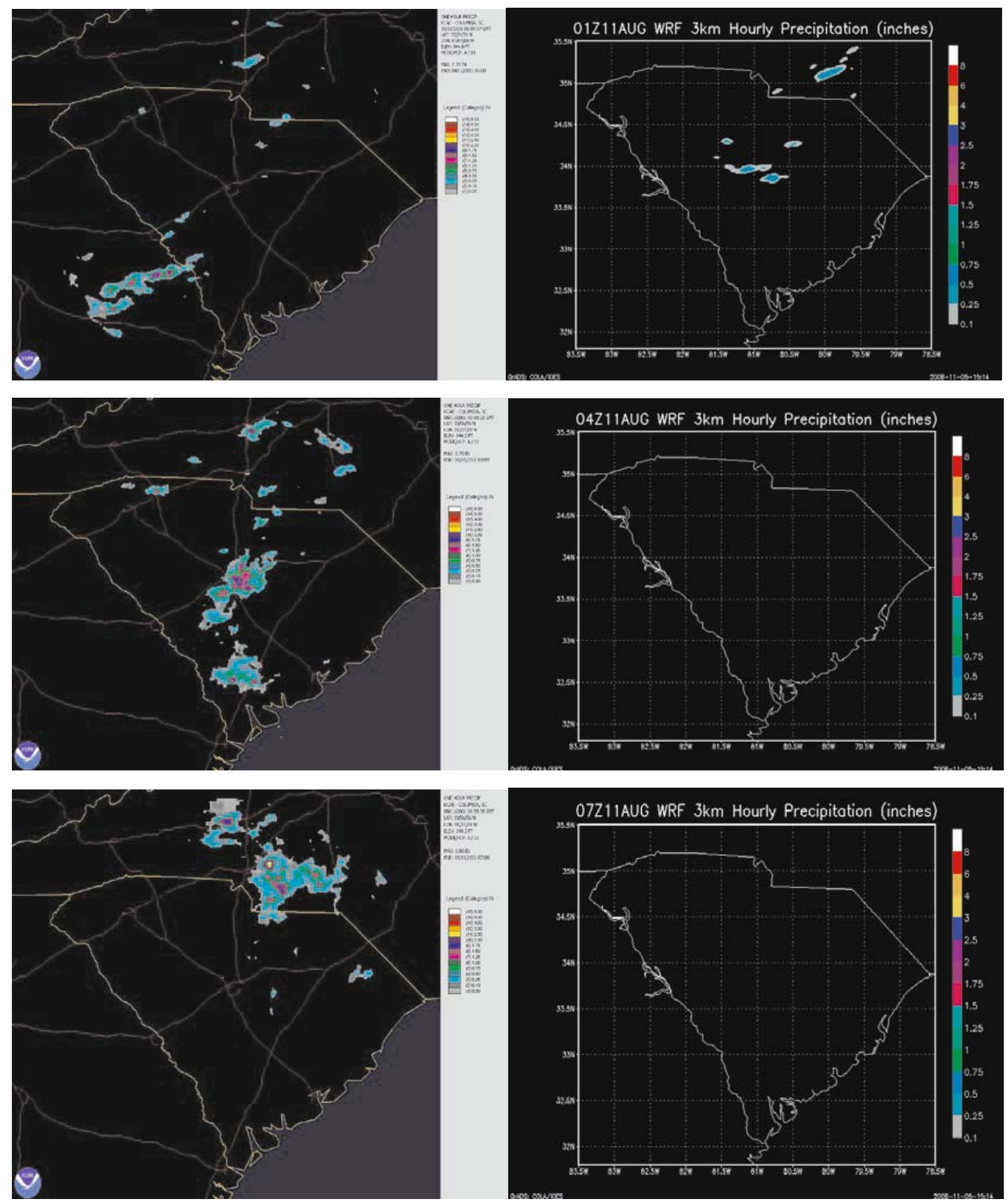

Figure 17. NEXRAD one hour precipitation (left) compared to WRF forecast hourly precipitation (right) for $0100 \mathrm{Z}$ 8/11/2001 to 0700Z 8/11/2001 (2000 EST 8/10/2001-0200 EST 8/11/2001). Scale 0-8 inches (0 to $203.2 \mathrm{~mm}$ ).

WRF simulation failed to capture the precipitation in the Sandhills. This problem was present in all three domains, regardless of the fact that the two outer domains use grid scale and sub-grid scale effects on precipitation forecasts. Shortly after sunset at $0100 \mathrm{Z}$ August 11, convection has ceased both along the coast and along the mountains, while convection has increased in intensity along 


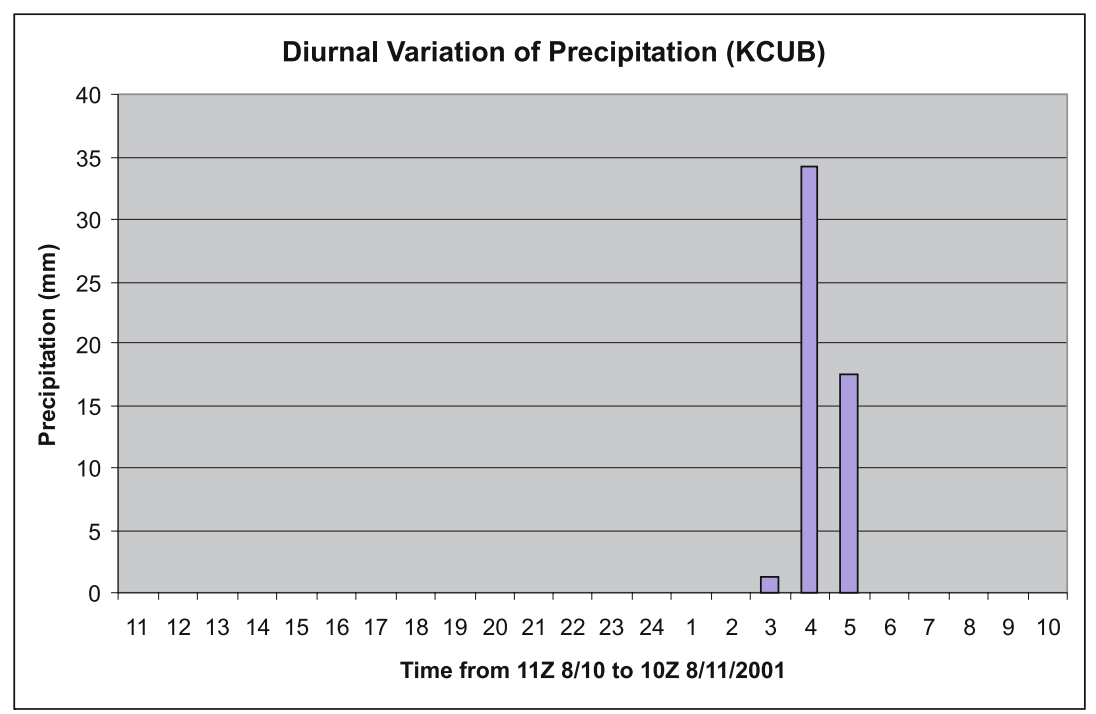

Figure 18. Precipitation ( $\mathrm{mm}$ ) time history at KCUB, Columbia, SC.
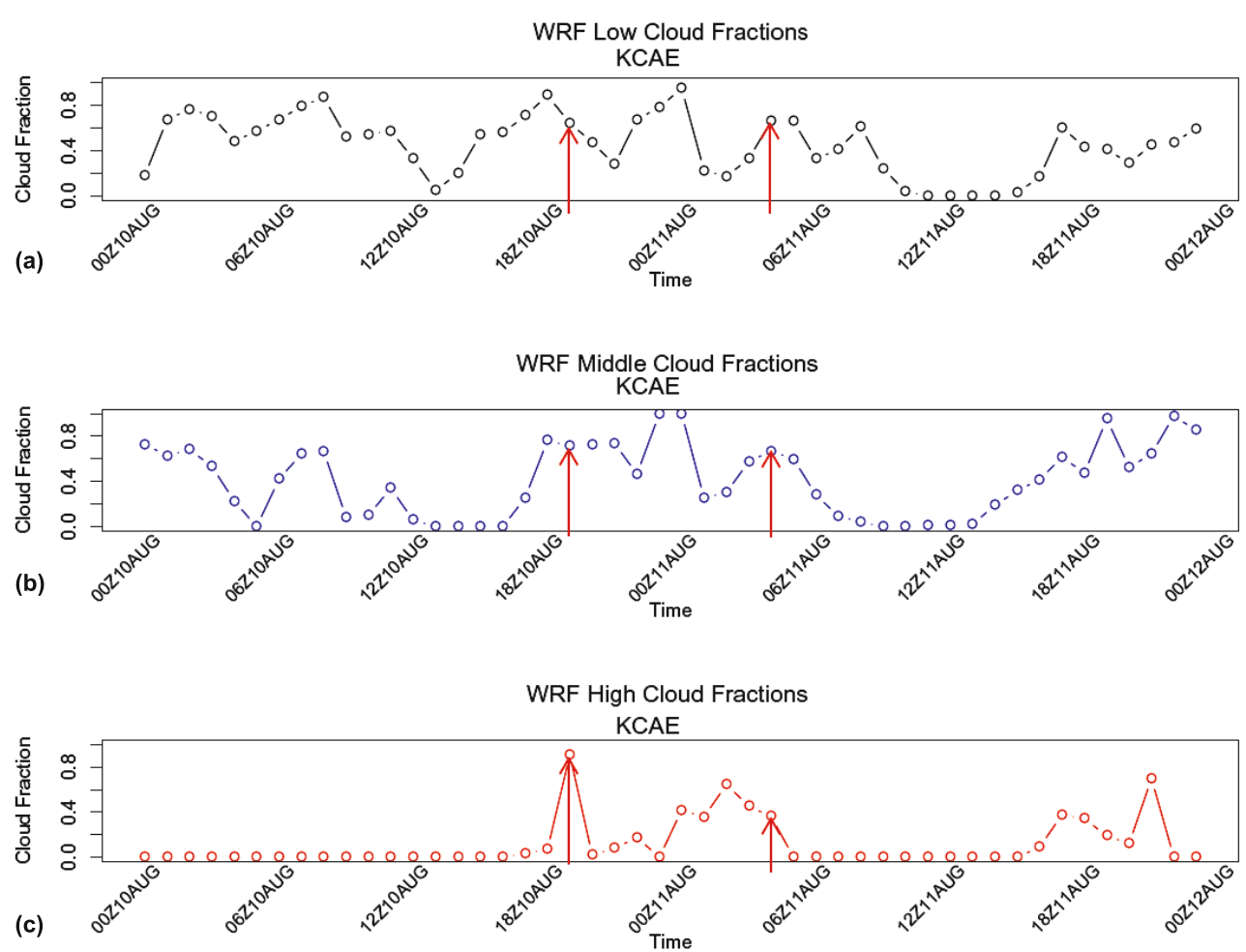

Figure 19. WRF forecasts of (a) low cloud fraction, (b) middle cloud fraction and (c) high cloud fraction from $0000 \mathrm{Z}$ 10 August 2001 to $2300 \mathrm{Z} 11$ August 2001 at KCAE, Columbia, SC. Times marked with arrows indicate times of observed precipitation recorded at the station.

the southern edge of the Sandhills (figure 13c). The convection in this region is probably the result of surface heat flux gradients caused by the difference in heat capacities between sand and clay. This gradient provides lifting for convective initiation along the Sandhills, given moisture availability and instability. The convection that forms near the southern edge of the Sandhills moves to the northwest along the sand/clay boundary or can move off the Sandhills impacting areas along the southeast coast. In this case, by $0400 \mathrm{Z}$ (figure 13d), a group of storms has advanced northward along the Sandhills to Columbia, SC, becoming more intense along the way. The NEXRAD one hour precipitation confirms that precipitation fell at KCUB and KCAE around $0400 \mathrm{Z}$, but the WRF 

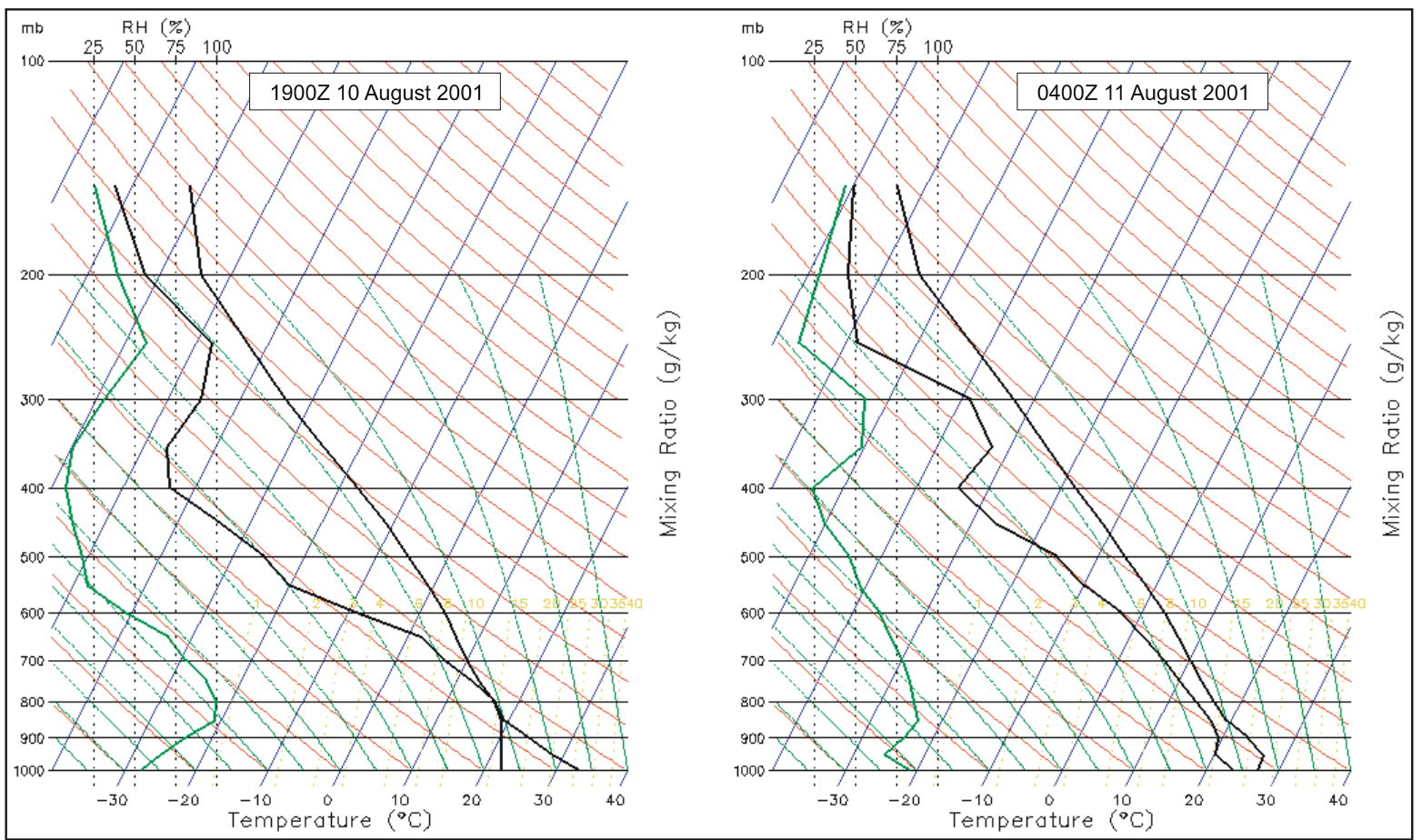

Figure 20. WRF forecast skew-T graphs overlaid with WRF forecast relative humidity profile at Columbia, SC for $1900 \mathrm{Z}$ 10 August 2001 (left) 0400 Z 11 August 2001 (right).

hourly forecasts fail to capture any precipitation occurring during the time period from $0100 \mathrm{Z}$ to $0700 \mathrm{Z}$ on August 11, 2001 as shown in figure 17. Convection at $0400 \mathrm{Z}$ was very intense, while earlier the same day there was no convection present in the area, and no precipitation was recorded at the ASOS station (KCUB) in Columbia, SC (figure 18). The amount recorded at this station at $2300 \mathrm{EST}(0400 \mathrm{Z})$ was $1.35^{\prime \prime}(34 \mathrm{~mm})$. This convection was highly localized over the Sandhills as can be seen from the regional distribution of the nocturnal precipitation. Precipitation was not observed at other weather stations through the night, and Columbia (KCUB) recorded the maximum precipitation as the storms reached maturity. During the whole night of August 10, there was no precipitation anywhere else besides the Sandhills. This suggests that the formation of storms on this night in this region was probably the result of the differences in soil type between the Sandhills and adjacent regions. This is likely the result of the heat flux gradient caused by differences in soil thermal capacity. As daytime heating begins clay soil tends to heat slower than the sand based soils. As noted by Boyles et al (2007), there is a difference in surface latent heat flux of about $100-200 \mathrm{~W} \mathrm{~m}^{-2}$ between the Sandhills and the surrounding claybased soils. As noted previously, the difference in sensible heat flux between soil types is not always captured by forecast models. These heat flux gradients allow for convection to form in the absence of synoptic forcing throughout the day. Weaker clouds formed by this process can last further into the night and become convective through the process of cloud radiation interaction, described previously, while the heat flux gradient remains to provide further lifting into the night. We believe that the reason for this underprediction in the Sandhills region could be from the inability of the model land use physics to properly represent horizontal gradients in surface turbulent heat fluxes caused by gradients in soil type, between sand and clay, in this case. The variations in surface heat flux generate a circulation similar to a sea breeze circulation, however while the circulation generates lift to form clouds in the Sandhills region, the influence of the heat flux circulation is negligible in the presence of larger scale forcing. The heat flux process essentially initiates convection during the day time in the absence of any frontal dynamics by providing the lifting mechanism for the formation of clouds. We hypothesize that after the sun sets, cloudradiation interaction causes the initial clouds to grow into deep convection in the Sandhills. We also hypothesize that while current models cannot fully capture the heat flux gradients that initiate the process of forming day time convection in the Sandhills, the model physics has limitations in simulating cloud radiation interaction during the night.

In an attempt to evaluate this theory we analyzed WRF cloud fractions and the model temperature, dew point and relative humidity profiles 

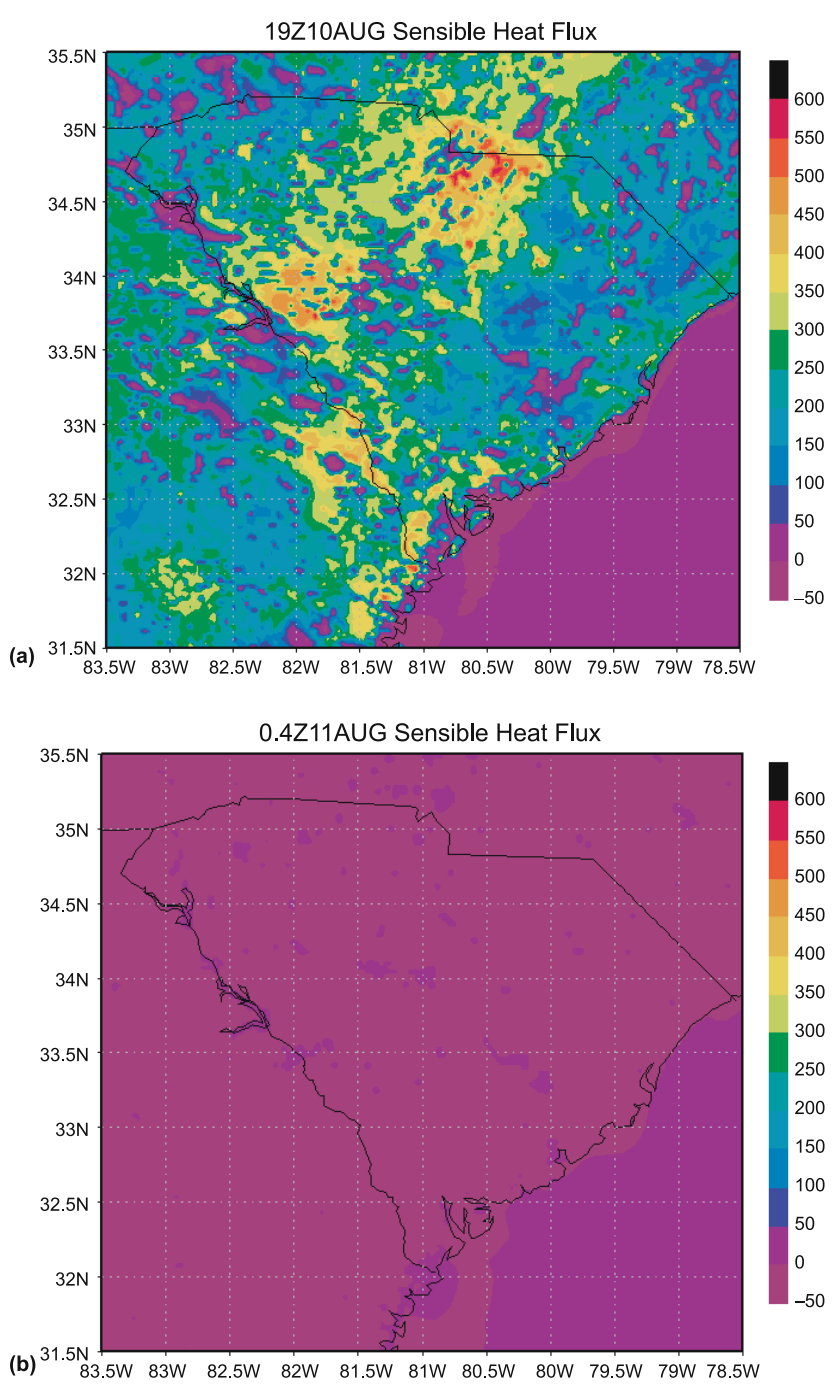

Figure 21. WRF forecast sensible heat flux across the South Carolina for (a) 1900 Z 10 August 2001 and (b) 0400 Z 11 August 2001.

for Columbia, SC along with the sensible heat flux across South Carolina. In this analysis, we will look at two times of observed convection. NEXRAD one hour precipitation recorded rain falling at Columbia at $1900 \mathrm{Z}$ (1400 EST) 10 August 2001 and $0400 \mathrm{Z} 11$ August 2001 (2300 EST 10 August 2001). For this discussion we will denote $1900 \mathrm{Z} 10$ August 2001 as T1 and 0400 Z 11 August 2001 as T2. As noted previously, the WRF simulation captured the precipitation occurring in the area at T1 but failed to capture the precipitation occurring at T2, either in the area or at the station. Since the times in question are observed convective precipitation events which occurred in the absence of larger scale forcing, we can assume that there are no cloud layers that we can associate with stratiform precipitation present at Columbia for both times. Convective clouds are known to grow from low cloud levels to high cloud levels. Therefore, we can judge that the simulation has generated a convective cloud if the cloud fractions at all levels in a cell is of a high value. In our case, we define the simulation as generating a convective cloud if the simulated cloud fractions are $\geq 0.5$ at all levels. Figure 19 is a time series of simulated low, middle and high cloud fractions for KCAE from $0000 \mathrm{Z} 10$ August 2001 to $0000 \mathrm{Z} 12$ August 2001. Red arrows in figure 19 indicate times of observed precipitation. At T1, notice that the low and middle cloud fractions are 0.6 and 0.75 , respectively, while the high cloud fraction is close to one at this time. By our definition, the WRF simulation had generated a convective cloud at or near Columbia at T1. At this time the simulation generated precipitation matching the observed precipitation at Columbia. At $\mathrm{T} 2$, the low and middle cloud fractions were both greater than 0.6 , yet the high cloud fraction remained at 0.4 . Therefore, by our definition the simulation has produced clouds close to or at Columbia that are not convective. However, during this time the model generated no precipitation at Columbia, when the hourly precipitation recorded for Columbia was $1.35^{\prime \prime}(34 \mathrm{~mm})$. In both cases, the land use physics in the simulation generated clouds, but the model failed to capture the observed night precipitation. However, the clouds present at night could have remained from precipitation which occurred in the model during the day. Figure 20 shows the model skew- $T$ plots with the relative humidity overlaid. In both cases, the model environment was moist and unstable, which would have allowed convection to occur given an available lifting mechanism. During the day, the sensible heat flux gradient provided the lifting mechanism along the Sandhills and was also captured by the model (figure 21a). This sensible heat flux gradient should have persisted into the night, but the WRF modeled sensible heat flux showed no gradient present, providing no lifting mechanism for convection in the modeled atmosphere (figure $21 \mathrm{~b}$ ).

As the sand and clay soils cool there is a net release of radiation into the atmosphere. As demonstrated previously clay soil begins to release heat during the early evening hours. This release of heat contributes to the development of a surface heat flux gradient, which generates new clouds, but can also serve to warm the bottom of clouds already present from the combined surface heat flux gradient and daytime heating effects. From this point shallow clouds generated during the day tend to grow through entrainment by warming at the base of the cloud and cooling at the top. Since the clay soil begins to release energy later than the sandy soil, this growth process can continue into the night, resulting in isolated convective precipitation during the night hours. From the analysis of WRF simulated cloud fractions it is evident that while the simulation generates some 
clouds at night, it does not reproduce the nocturnal sensible heat flux gradient which would allow cloud radiation interaction to deepen the clouds present or provide the lifting mechanism to form new convective clouds. Although the model was able to predict reasonable convection in this region during the day, it failed to predict deep convection during night time when cloud-radiation interaction is a significant mechanism for cloud growth. However, this conclusion is the result of only one model simulation of a specific case. Further simulations of other observed convection with different cumulus and radiation schemes should be performed to provide additional evidence for or against this conclusion.

\section{Conclusions}

The Carolina Sandhills region is an area where deep convection occurs during summers. Convection is generally initiated by the demonstrated horizontal sensible heat flux gradients generated by the difference in heat capacities between sand and clay. This gradient creates an ageostrophic circulation similar to a sea-breeze. Shallow clouds which form through this process are enhanced by instability caused by daytime heating of the surface. Some of these clouds that are not convective during the daytime hours last into the night, when cloudradiation interaction could cause the cloud to grow through entrainment into deep convective clouds. In addition to cloud-radiation interaction, the horizontal heat flux gradients present during the day remains active during the night because of differing soil heat capacities, allowing for additional clouds to form. These clouds in turn are possibly enhanced by cloud-radiation interaction. These effects allow for more precipitation to occur during the night hours of summer along the Sandhills, as suggested by the climatological analysis of precipitation from several stations along the Sandhills.

From a climatological model forecast analysis, it is evident that the $12 \mathrm{~km}$ resolution NAM Eta model is not able to predict the night time precipitation. A case study of numerical simulation presented in this paper indicates the limitations of the WRF model in predicting nocturnal convection. The mesoscale model does create the clouds at night and some measure of precipitation, but it fails to grow any available clouds into deep convective clouds.

\section{Acknowledgements}

Funding for this research was provided by the Division of Atmospheric Sciences, National Science Foundation under the Grants ATM-0233780 and ATM-0342691. We thank Ryan Boyles and Mark Brooks of the State Climate Office of North Carolina for providing technical assistance.

\section{References}

Arakawa A 2004 The cumulus parameterization problem: Past, present and future; J. Climate 17 2493-2525.

Arya S P 2001 Introduction to Micrometeorology, 2nd edn, Academic Press, 415 pp.

Bony S and Emanuel K 2005 On the role of moist processes in tropical intraseasonal variability: Cloud-radiation and moisture convection feedbacks; J. Atmos. Sci. 62 2770-2789.

Boyles R, Sims A and Raman S 2007 Sensitivity of mesoscale surface dynamics to surface soil and vegetation contrasts over the Carolina Sandhills; Pure Appl. Geophys. 164 1547-1576.

Hong X, Leach M J and Raman S 1995 A sensitivity study of convective cloud formation by vegetation forcing with different atmospheric conditions; J. Appl. Meteor. 34 2008-2028.

Koch S and Ray C 1997 Mesoanalysis of summer time convergence zones in central and eastern North Carolina; Wea. Forecasting 12 56-77.

Mahfouf J, Richard E and Mascart R 1987 The influence of soil and vegetation on the development of mesoscale circulations; J. Climate Appl. Meteor. 26 1483-1495.

Marshall C, Crawford K, Mitchell K and Stensrud D 2003 The impact of the land surface physics in the operational NCEP Eta model on simulating the diurnal cycle: Evaluation and testing using Oklahoma Mesonet Data; Wea. Forecasting 18 748-768.

Moore D S and McCabe G P 2006 Introduction to the Practice of Statistics, 5th edn, W. H. Freeman and Company, $896 \mathrm{pp}$.

Ookouchi Y, Segal M, Kessler C and Pielke R A 1984 Evaluation of soil moisture effects on the generation and modification of mesoscale circulations; Mon. Wea. Rev. 112 2281-2292.

Raman S, Sims A, Ellis R and Boyles R 2005 Numerical simulations of mesoscale circulations in a region of contrasting soil types; Pure Appl. Geophys. 162 1689-1714.

Segal M, Avissar R, McCumber M C and Pielke R A 1988 Evaluation of vegetation effects on the generation and modification of mesoscale circulations; J. Atmos. Sci. $\mathbf{4 5}$ $2268-2293$. 